\section{Delirium tremens}

Helga Peter ${ }^{1}$ und Thomas Penzel ${ }^{2}$

${ }^{1}$ Marburg, Deutschland

${ }^{2}$ Interdisziplinäres Schlafmedizinisches Zentrum, Charité Universitätsmedizin Berlin, Berlin, Deutschland

\section{Synonyme}

Alkoholdelir

\section{Englischer Begriff}

alcoholic delirium

\section{Definition}

Entzugssyndrom bei chronischem Alkoholkonsum. Es entsteht nach 5-jährigem oder länger dauerndem Alkoholabusus und ist durch eine Kombination von psychotischen Symptomen wie Desorientiertheit, Halluzinationen, Illusionen, Euphorie und Angst mit somatischen Symptomen wie starkem Tremor, Unruhe, Schlaflosigkeit, profusem Schwitzen und Fieber gekennzeichnet. Unbehandelt kommt es nach 2-10 Tagen zu einem \ ,Terminalschlaf“, der bis zu 30 Stunden dauern kann. Bei Fortsetzung des Alkoholmissbrauchs kann das Delirium wiederholt auftreten; vor Einführung der intensivmedizinischen Behandlung lag die Mortalität bei ca. $20 \%$.

Siehe auch $\triangleright$,Alkoholkrankheit“. 